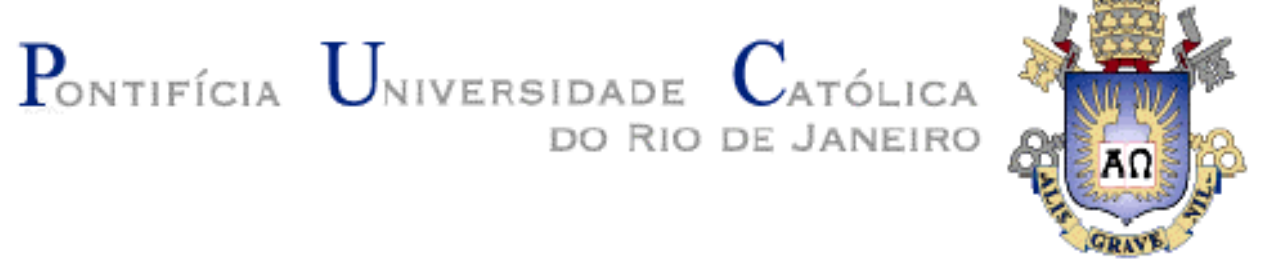

Tiago Barbosa Gloria

\title{
A Internacionalização de Empresas de Comércio Eletrônico: Estudo de Caso da B2W - Companhia Global do Varejo
}

Dissertação de Mestrado

Dissertação apresentada ao Programa de Pósgraduação em Administração de Empresas da PUCRio como requisito parcial para obtenção do título de Mestre em Administração de Empresas.

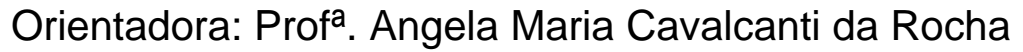


Tiago Barbosa Gloria

\section{A Internacionalização de Empresas de Comércio Eletrônico: Estudo de Caso da B2W - Companhia Global do Varejo}

Dissertação apresentada como requisito parcial para obtenção do grau de Mestre pelo Programa de Pósgraduação em Administração de Empresas da PUC-Rio. Aprovada pela Comissão Examinadora abaixo assinada.

Profa. Angela Maria Cavalcanti da Rocha

Orientadora

Departamento de Administração - PUC-Rio

Prof. Jorge Ferreira da Silva

Departamento de Administração - PUC-Rio

Prof. Renato Dourado Cotta de Mello

COPPEAD - UFRJ

Profa. Mônica Herz

Vice-Decana de Pós-Graduação do CCS

Rio de Janeiro, 12 de abril de 2012 
Todos os direitos reservados. É proibida a reprodução total ou parcial do trabalho sem autorização da universidade, do autor e da orientadora.

Tiago Barbosa Gloria

Graduou-se em Comunicação Social com ênfase em Jornalismo na Universidade do Estado do Rio de Janeiro (UERJ) em 2007. Com experiência nas áreas de Recursos Humanos e Tecnologia da Informação, atuou profissionalmente na Lojas Americanas por três anos, posteriormente trabalhou como coordenador de TI na B2W, controlada por Lojas Americanas, durante dois anos. Atualmente trabalha como coordenador de Recursos Humanos na empresa Dufry do Brasil.

Ficha Catalográfica

Gloria, Tiago Barbosa

A internacionalização de empresas de comércio eletrônico: estudo de caso da B2W - Companhia Global do Varejo / Tiago Barbosa Gloria ; orientadora: Angela Maria Cavalcanti da Rocha. - 2012.

85 f. : il. (color.) ; $30 \mathrm{~cm}$

Dissertação (mestrado)-Pontifícia Universidade Católica do Rio de Janeiro, Departamento de Administração, 2012.

Inclui bibliografia

1. Administração - Teses. 2. eCommerce. 3. Processo de internacionalização. 4. Teorias de internacionalização. I. Rocha, Maria Angela Cavalcanti da. II. Pontifícia Universidade Católica do Rio de Janeiro. Departamento de Administração. III. Título. 
“São as conquistas do filho que atestam o êxito dos pais.” - Eliezer Batista. Agradeço aos meus pais, Antonio e Leda, que mesmo não tendo oportunidade de acesso a educação formal, souberam transmitir aos filhos um profundo gosto pelo conhecimento.

"Todo homem, por natureza, quer o saber." Aristóteles. 


\section{Agradecimentos}

Primeiramente gostaria de agradecer a Deus por essa oportunidade de cursar e concluir um curso de Mestrado.

À minha orientadora, Prof. Ângela da Rocha, pela constante provocação na busca de respostas para as questões atinentes ao tema investigado. Durante o trabalho, foi acolhedora e sempre atendeu minhas solicitações com presteza.

Agradecimento aos meus pais, Antônio e Leda e meu irmão Diego, por quem tenho muito respeito, carinho, admiração e amizade, aqueles que amarei para sempre e a quem devo muito da pessoa que sou.

À empresa B2W - Companhia Global do Varejo, em especial a Anna Saicalli que me incentivou nesse projeto. À minha equipe na Dufry que soube me compreender na reta final e que me apoiou nos momentos difíceis.

À Marcela Neves, Pedro Abondanza e Roberto Alves com quem compartilhei momentos de sofrimento e diversão dos últimos dois anos.

Agradeço também aos amigos, amigas, familiares que souberam, tantas vezes, compreender pacientemente as minhas repetidas ausências.

A todos os professores do IAG e demais funcionários da PUC-Rio pela dedicação e preocupação em sempre disponibilizar um ambiente agradável aos alunos.

E à Michelle Noronha, minha maior incentivadora, cujo apoio foi fundamental para conclusão deste projeto e com quem espero compartilhar muitas outras alegrias. 


\section{Resumo}

Gloria, Tiago Barbosa; Rocha, Ângela Maria Cavalcanti da. A Internacionalização de Empresas de Comércio Eletrônico: Estudo de Caso da B2W - Companhia Global do Varejo. Rio de Janeiro, 2012. 85p. Dissertação de Mestrado - Departamento de Administração, Pontifícia Universidade Católica do Rio de Janeiro.

O movimento de internacionalização de empresas brasileiras iniciou-se pelo setor industrial; a internacionalização das empresas de varejo é um fenômeno mais recente no país. Assim, pesquisas sobre o processo de internacionalização de empresas varejistas brasileiras não são muito numerosas no Brasil, sobretudo sobre empresas de comércio eletrônico. Nesse contexto, o estudo objetivou investigar, através do método de estudo de caso da empresa B2W - Companhia Global do Varejo, o processo de interncaionalização de uma empresa brasileira de comércio eletrônico - suas motivações, como ela expandiu seus negócios no exterior, obstáculos enfrentados e fatores facilitadores do processo. Atuar internacionalmente foi uma forma de ampliação de mercado e diversificação para redução de riscos e hoje faz parte da estratégia de crescimento da empresa. O estudo utilizou dados secundários provenientes de teses, dissertações, artigos e Internet, além de dados primários coletados em entrevistas em profundidade com os principais executivos da empresa. A análise dos dados mostrou que as estruturas teóricas registradas nesta tese foram identificadas no processo de internacionalização da empresa estudada.

\section{Palavras-chave}

eCommerce; processo de internacionalização; teorias de internacionalização 


\section{Abstract}

Gloria, Tiago Barbosa; Rocha, Ângela Maria Cavalcanti da. The Internationalization of E-Commerce Firms: A Case Study of B2W Companhia Global do Varejo. Rio de Janeiro, 2012. 85p. MSc. Dissertation - Departamento de Administração, Pontifícia Universidade Católica do Rio de Janeiro.

The movement of internalization of brazilian enterprises is primarily characterized by the displacement of industrial companies; the internalization of retail business is a more recent phenomenon. Thus, studies on the internalization process of brazilian retail companies are not numerous yet in the country. In this context, the study aimed to investigate, using the method of case study of B2W Companhia Global do varejo, the internalization process of a brazilian eCommerce company - their motives, how it expanded their business abroad and what were their main obstacles that have been faced and the facilitating factors of the process. Acting abroad was a way for widening markets and diversifying risks for the enterprise, and nowadays, it is the focus of its growing strategy. This study has utilized secondary data retrieved from theses, dissertation, articles and internet, besides primary data collected through in-depth interviews with main company executives. Data analysis showed that theoretical framework employed in this work was present in the internalization process of the company studied.

\section{Keywords}

eCommerce; internationalization process; internationalization theories 


\section{Sumário}

1. Introdução 13

1.1. Objetivos 15

1.1.1. Objetivo Geral 15

1.1.2. Objetivos Específicos $\quad 15$

1.2. Organização do Estudo 15

2. O Processo de Internacionalização de Empresas de Internet 16

2.1. Teorias sobre Internacionalização de Empresas 16

2.1.1. Teoria da Internacionalização 16

2.1.2. Paradigma Eclético 19

2.1.3. Teoria de Uppsala 23

2.1.4. Justaposição de Teorias e Proposições 28

2.2. Internacionalização de Empresas de Internet 30

2.2.1. Fontes de Incerteza que Influenciam na Tomada de Decisão Rumo à Internacionalização 31

2.2.2. O Tamanho do Mercado como Fator Moderador 37

3. Metodologia de Pesquisa 38

3.1. Seleção do Caso 39

3.2. Coleta de Dados 39

3.3. Análise dos Dados 41

4. Caracterização do Mercado e da Empresa 43

4.1. Caracterização do Mercado 43

4.1.1. Visão Geral do Setor 44

4.1.2. Linha do Tempo de E-Commerce 45

4.1.3. Crescimento do Comércio Eletrônico no Brasil 46

4.2. Apresentação da Empresa 53

4.2.1. A Lojas Americanas $\quad 54$

4.2.2. A B2W 54

4.2.3. As Marcas da Companhia 56

4.2.4. Linha do Tempo da B2W 59

5. A Internacionalização da B2W 60

5.1. Motivações $\quad 60$

5.1.1. Fatores Macroeconômicos 60

5.1.2. Pressões Competitivas 62

5.1.3. Declínio de Vendas no Comércio Local 63

5.1.4. Orientação Global 64

5.1.5. Oportunidade no Mercado Externo 65

5.1.6. Facilidade de Acesso 66 
5.2. Estratégias Utilizadas $\quad 66$

5.2.1. Seleção de Mercados 66

5.2.2. Modo de Entrada no Exterior 67

5.2.3. Implantação Operacional 68

5.3. Análise do Caso à Luz das Teorias Estudadas 68

5.3.1. Motivações para Início do Processo de Internacionalização $\quad 69$

5.3.2. Seleção de Mercados Externos $\quad 70$

5.3.3. Escolha do Modo de Entrada $\quad 74$

5.3.4. Fatores Dificultadores $\quad 75$

5.3.5. Fatores Facilitadores 76

6. Conclusões 78

6.1. Síntese do Estudo 78

6.2. Conclusões 78

6.3. Limitações do Estudo 80

6.4. Recomendações $\quad 80$

6.4.1. Para a Empresa 80

6.4.2. Para Outras Empresas de Comércio Eletrônico 81

6.4.3. Para Futuros Pesquisadores 81

7. Referências Bibliográficas 82 


\section{Lista de figuras}

Figura 1: Modelo Estratégico Internacional de Expansão de Varejistas

Figura 2: Modelo do Processo de Internacionalização

Figura 3: A Model of Factors Influencing the Retail

Internationalization Process

Figura 4: Operational Internationalization

Figura 5: Motivos para internacionalização e empresas de eCommerce

Figura 6: Distribuição de acessos e difusão banda larga por região demográfica

Figura 7: Estrutura societária da empresa

Figura 8: Estrutura societária da B2W

55

Figura 9: Marcas sob gestão da B2W 


\section{Lista de gráficos}

Gráfico 1: Faturamento do e-commerce no Brasil 47

Gráfico 1: Evolução do acesso banda larga no Brasil 48

Gráfico 3: Evolução da difusão do acesso banda larga 49

Gráfico 4: Projeção dos acessos banda larga no Brasil e outros 6 países

Gráfico 5: Projeção de acessos banda larga fixo e móvel 50

Gráfico 6: Histórico de Cotações BTOW3 61

Gráfico 7: Participação da B2W no faturamento do e-commerce 63

Gráfico 8: Market Share B2W no eCommerce do Brasil 64 


\section{Lista de quadros}

Quadro 1: Evolução do acesso à internet no mundo

Quadro 2: E-commerce market share per country

52

Quadro 3: E-consumers no Brasil

53

Quadro 4: Classificação dos países nas dimensões de Hofstede

70

Quadro 5: Classificação risco-país

73 